\title{
Self-Devouring Growth
}

CRITICAL GLOBAL HEALTH:

EVIDENCE, EFFICACY, ETHNOGRAPHY

A series edited by Vincanne Adams and João Biehl 
This page intentionally left blank 

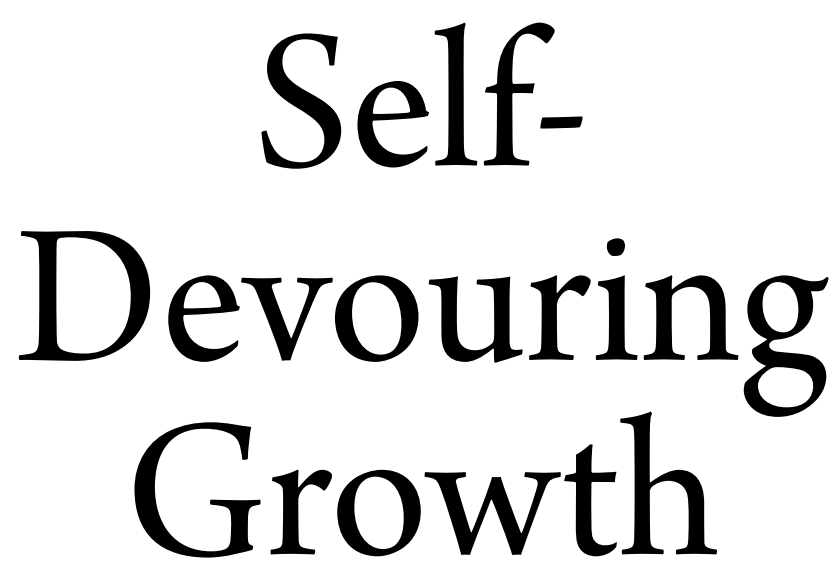

A PLANETARY PARABLE

AS TOLD FROM SOUTHERN AFRICA

Julie Livingston

DUKE UNIVERSITY PRESS

Durham and London

2019 
(C) 2019 Duke University Press

All rights reserved

Printed in the United States of America on

acid-free paper @

Designed by Amy Ruth Buchanan

Typeset in Arno by

Tseng Information Systems, Inc.

Library of Congress Cataloging-in-Publication Data

Names: Livingston, Julie, author.

Title: Self-devouring growth : a planetary parable as told

from Southern Africa / Julie Livingston.

Other titles: Critical global health.

Description: Durham : Duke University Press, 2019. |

Series: Critical global health: evidence, efficacy, ethnography |

Includes bibliographical references and index.

Identifiers: LCCN 2019009525 (print)

LCCN 2019980595 (ebook)

ISBN 9781478005087 (hardcover)

ISBN 9781478006398 (paperback)

ISBN 9781478007005 (ebook)

Subjects: LCSH: Economic development-Environmental

aspects - Botswana. | Consumption (Economics) -

Environmental aspects - Botswana.

Classification: LCC HC930.Z9 E5 2019 (print) | LCC HC930.Z9

(ebook) | DDC 388.96883-dc23

LC record available at https://lccn.loc.gov/2019009525

LC ebook record available at https://lccn.loc.gov/2019980595

Cover art: James Cullinane, Rain Drawing 2, 2017.

Ink and acrylic on panel, $12 \times 9$ in. Courtesy of the artist and Robert Henry Contemporary, New York. 
FOR HAZEL 
This page intentionally left blank 